\title{
QUEIJOS: ASPECTOS QUÍMICOS, BIOQUÍMICOS E MICROBIOLÓGICOS
}

\section{Katia S. P. Perry*}

Serviço de Química e Radioquímica, Comissão Nacional de Energia Nuclear, Centro de Desenvolvimento da Tecnologia Nuclear, CP 941, 30123-970 Belo Horizonte - MG

Recebido em 23/1/03; aceito em 23/6/03

CHEESE: CHEMICAL, BIOCHEMICAL AND MICROBIOLOGICAL ASPECTS. This article presents a brief historical outline of cheese manufacture. Chemical, biochemical and microbiological aspects are presented: the main constituents of curd, the reactions involved in the development of flavour, and the role of micro-organisms and enzymes in the fermentation and maturation processes. A brief description of the characteristics of some cheeses is also given.

Keywords: cheeses; chemistry; micro-organisms.

\section{INTRODUÇÃO}

A história do queijo remonta a tempos antiquíssimos, embora muitos especialistas considerem a Idade Média como o marco inicial da sua fabricação. Há relatos de consumo de leite solidificado datando de 7.000 anos a.C. e achados arqueológicos revelam a existência de queijos feitos a partir de leite de vaca e de cabra 6.000 anos a.C.. Murais em tumbas egípcias mostram cenas de fabricação de queijo no Antigo Egito e a Bíblia cita este produto em mais de uma passagem do Velho Testamento. Nos escritos de Aristóteles há referência a queijos feitos de leite de égua e jumenta ${ }^{1}$.

Os antigos gregos creditavam a descoberta do queijo a Aristeu, rei da Arcádia, filho de Apolo e Cirene. Uma lenda a atribui a um nômade árabe que, em uma de suas jornadas pelo deserto, teria levado como alimento tâmaras secas e um pouco de leite em um cantil feito de estômago seco de carneiro. Depois de um certo tempo, quando foi beber o leite, descobriu que ele havia se transformado em um sólido de sabor agradável. Independente de como ele foi descoberto, porém, o que se sabe é que o queijo tem sido utilizado ao longo do tempo como uma forma de preservação do leite.

Durante o Império Romano a produção de queijos aperfeiçoouse, alcançando um alto padrão. A técnica de maturação já havia sido desenvolvida e as casas possuíam um espaço próprio para a fabricação e a "cura" dos queijos. Estes eram servidos tanto à nobreza, em seus freqüentes banquetes em Roma, quanto aos soldados das Legiões Romanas, nas mais longínquas fronteiras do Império. Na Idade Média os monges cristãos, especialmente os Trapistas, transformaram a fabricação de queijos em uma verdadeira arte, introduzindo muitas das variedades consumidas ainda hoje. Durante a Renascença, o queijo perdeu parte de sua popularidade por ser considerado pouco saudável, mas esta foi readquirida ao longo do tempo ${ }^{1}$.

Em 1267 foi fundada na França a primeira "fruitières", ancestral das cooperativas laticinistas, que produzia os queijos Beaufort, Emmenthal e Comté. No século XIX iniciou-se a produção em massa de queijos mas, somente no início do século XX foi aberta a primeira grande queijaria na França.

Embora o processo básico de fabricação de queijos seja comum a quase todos, variações na origem do leite, nas técnicas de processamento e no tempo de maturação criam a imensa variedade conhe-

*e-mail: kspp@cdtn.br cida - cerca de 1.000 tipos, sendo que só na França fabricam-se 400 deles.

No Brasil o consumo anual de queijos é de 2,3 $\mathrm{Kg}$ per capita ${ }^{2}$. Este valor vem crescendo, mas ainda é pequeno quando comparado ao da Argentina ou de países europeus. O estado de Minas Gerais é o maior produtor brasileiro de queijos, com cerca de 200 t/ano, e responde pela metade do consumo nacional. A maior parte dessa produção é feita em pequenas e médias queijarias. Em algumas regiões do estado, o setor queijeiro emprega cerca de 30 mil famílias de pequenos proprietários rurais e movimenta mensalmente algo em torno de 10 milhões de reais ${ }^{2}$. Dados de $2001^{3}$ indicam que a produção leiteira no Brasil é de cerca de 20 milhões de litros, sendo $60 \%$ deste total destinado à fabricação de queijos, a qual atinge $450 \mathrm{mil}$ toneladas anuais. Estes dados ilustram bem a importância social e econômica do produto.

Neste artigo pretende-se apresentar alguns aspectos da técnica de produção de queijos, sua variedade, alguns dos processos químicos e bioquímicos envolvidos, além de apontar algumas questões relevantes envolvendo saúde pública e segurança alimentar.

\section{TECNOLOGIA BÁSICA E COMPOSIÇÃO QUÍMICA}

O queijo é um concentrado lácteo constituído de proteínas, lipídios, carboidratos, sais minerais, cálcio, fósforo e vitaminas, entre elas A e B. É um dos alimentos mais nutritivos que se conhece: um queijo com $48 \%$ de gordura contém cerca de $23-25 \%$ de proteína o que significa que, em termos de valor protéico, $210 \mathrm{~g}$ desse produto eqüivalem a $300 \mathrm{~g}$ de carne ${ }^{1}$. Os minerais participam do processo de coagulação do leite, influenciando a textura do queijo. O líquido residual, cujo teor varia com o tipo de queijo, é chamado lactosoro; boa parte dele é eliminada durante o processo de fabricação e aproveitada como matéria-prima na produção de iogurtes, ricota e outros produtos.

A classificação dos queijos baseia-se em características decorrentes do tipo de leite utilizado, do tipo de coagulação, da consistência da pasta, do teor de gordura, do tipo de casca, do tempo de cura, etc.

Segundo o Ministério da Agricultura, Pecuária e Abastecimento (MAPA $)^{4}$, queijo é "o produto fresco ou maturado que se obtém por separação parcial do soro do leite ou leite reconstituído (integral, parcial ou totalmente desnatado) ou de soros lácteos, coagulados pela ação física do coalho, enzimas específicas de bactérias específicas, de ácidos orgânicos, isolados ou combinados, todos de qualida- 
de apta para uso alimentar, com ou sem agregação de substâncias alimentícias e/ou especiarias e/ou condimentos, aditivos especificamente indicados, substâncias aromatizantes e matérias corantes." A legislação complementa essa definição, reservando o nome queijo exclusivamente para produtos cuja base láctea não contenha gordura e/ou proteínas de outra origem.

A Organização Mundial de Saúde (OMS), classifica os queijos de acordo com seu teor em gordura, GMS, e seu teor de umidade, HBNG.

$$
\begin{gathered}
\mathrm{GMS}=\frac{m_{g}}{m_{t}-m_{g}} \times 100 \\
\mathrm{HBNG}=\frac{m_{u}}{m_{t}-m_{g}} \times 100
\end{gathered}
$$

onde $m_{g}, m_{u}, m_{t}$ são, respectivamente, a massa de matéria graxa, a massa úmida e a massa total, em gramas.

Tem-se assim escalas de vão de $\mathrm{HBNG}<1$ (queijos extra duros) a HBNG $>67$ (queijos macios) e GMS $>60$ (queijos muito gordurosos) a $\mathrm{GMS}<10$ (queijos não-gordurosos) ${ }^{5}$.

A fabricação de queijos envolve alguns procedimentos gerais e outros que são específicos de cada tipo. O leite utilizado na produção de queijos frescos tem, obrigatoriamente, que ser pasteurizado. Para aqueles que passam por um período de maturação antes de serem consumidos, o leite pode ou não ser utilizado cru, dependendo do tipo de queijo. A legislação brasileira, porém, exige que produtos derivados de leite cru sejam comercializados somente após quarentena de 60 dias. Essa legislação gera, às vezes, situações de difícil solução. É o caso, por exemplo, do queijo Minas artesanal, fabricado nas regiões das Serras da Canastra, Serro e Salitre, em Minas Gerais, desde os tempos coloniais. Acredita-se que o tempo de maturação, que é de 20 dias, associado ao fermento utilizado, conhecido como pingo, são capazes de eliminar as bactérias patogênicas que possam estar presentes no queijo que, de qualquer modo, não resiste à quarentena de 60 dias sem deteriorar-se. Essa situação já foi enfrentada por produtores de outros países, entre os quais a França que possui um grande número de queijos produzidos com leite cru. Lá, a solução do impasse veio da implantação de boas práticas de manejo do gado e higiene rigorosa em todas as etapas de produção do queijo garantindo, assim, a qualidade microbiológica do produto e preservando a saúde do consumidor. $\mathrm{O}$ mesmo vem sendo tentado em Minas Gerais com apoio do governo estadual e de organizações não-governamentais, inclusive com a participação de produtores franceses $^{2}$.

A tecnologia de fabricação compreende as seguintes etapas básicas $^{5}$ :

1. Coagulação do leite: pode ser feita diretamente pela flora microbiana do leite, ou pela adição de cultivo bacteriano apropriado (coalho ou fermento). Após um período de tempo, o leite fermentado transforma-se na coalhada;

2. Corte da coalhada, para liberação do lactosoro;

3. A massa obtida é colocada em formas e prensada, ou não, dependendo do queijo;

4. O queijo é salgado e, em seguida, embalado.

No caso de queijos que necessitam de maturação, esta pode ser feita antes ou após a embalagem; em alguns casos, o queijo é deixado maturar por um certo período depois do qual é embalado e levado para completar a maturação.

O leite destinado ao fabrico de queijos deve ser de boa qualidade e, tanto quanto possível, livre de contaminação bacteriana ou por agentes químicos como antibióticos, herbicidas, pesticidas, etc. No caso dos antibióticos, se estes forem administrados ao gado, passa- rão ao leite e poderão inibir a sua coagulação ou alterar o tempo de maturação dos queijos devido a alterações na microbiota láctica. De um modo geral, para fabricação de queijos duros e semiduros o leite também não deve ser homogeneizado; outros tipos de queijos exigem que a gordura seja homogeneizada sob a forma de 15 a $20 \%$ de nata. A homogeneização torna a gordura mais suscetível à ação das lipases facilitando, assim, a formação de ácidos graxos livres, os quais são constituintes fundamentais para o sabor dos queijos.

Às vezes, adiciona-se $\mathrm{CO}_{2}$ ao leite destinado ao fabrico de queijos; o objetivo é baixar o seu $\mathrm{pH}$, o que permite diminuir o tempo de fermentação ou, mantido este tempo, utilizar menor quantidade de coagulante.

A função do coalho, utilizado em todos os tipos de queijo exceto os frescos tipo "cottage", é coagular a caseína presente no leite ${ }^{5,6}$. A principal enzima responsável por essa ação é a renina, uma fosfoproteína de ação proteolítica presente no estômago de ruminantes jovens. Ela atua hidrolisando ligações peptídicas da caseína, transformando-a em para-caseína que precipita em presença de íons $\mathrm{Ca}^{2+}$ formando, então a coalhada. Este processo é dependente da temperatura, do $\mathrm{pH}$ e do teor de cálcio do leite. A temperatura ótima de ação do coalho é em torno de $40^{\circ} \mathrm{C}$, mas costuma-se utilizar temperaturas ligeiramente mais baixas (em torno de $35^{\circ} \mathrm{C}$ ) para evitar que a coalhada fique muito dura. Outro método de coagulação da caseína é adicionar ácido ao leite em quantidade suficiente para igualar o $\mathrm{pH}$ do meio ao ponto isoelétrico da proteína ( $\mathrm{pH} 4,5)$. Neste $\mathrm{pH}$ as micelas de caseína agregam-se e precipitam. Esse método fornece queijos de qualidade inferior aos produzidos pelo método enzimático.

Tradicionalmente os coalhos são de origem animal, principalmente bezerros e porcos mas, para atender às necessidades especiais de grupos como os vegetarianos e os muçulmanos, foram desenvolvidos coalhos de origem vegetal e microbiana. Coalhos de origem vegetal têm, em geral, bom desempenho, mas os queijos fabricados com eles costumam apresentar sabor amargo depois de algum tempo de armazenamento. Já os coalhos de origem microbiana têm características bastante semelhantes aos de origem animal ${ }^{5}$.

Durante a formação da coalhada podem ser adicionados, conforme a necessidade e o interesse do produtor, aditivos como $\mathrm{CaCl}_{2}$, nitratos, corantes, etc. $\mathrm{O} \mathrm{CaCl}_{2}$ aumenta o teor de íons $\mathrm{Ca}^{2+}$ no leite, acelerando a coagulação da caseína e ajudando a firmar o coágulo. É utilizado, principalmente, quando o teor de proteína no leite não é o ideal. Na fabricação de queijos com baixíssimo teor de gordura, adiciona-se $\mathrm{Na}_{2} \mathrm{PO}_{4}$ antes do $\mathrm{CaCl}_{2}$. Esse sal reage com o leite formando $\mathrm{Ca}_{3}\left(\mathrm{PO}_{4}\right)_{2}$ coloidal que aumenta a elasticidade do coágulo, funcionando como um substituto dos glóbulos de gordura do leite.

Nitrato de sódio ou de potássio tem a função de inibir a ação de contaminantes, especialmente bactérias do gênero Clostridium. O nitrato adicionado é reduzido a nitrito, pela ação da xantina oxidase, durante a maturação. $\mathrm{O}$ nitrito não inibe a ação das bactérias lácteas, mas impede o crescimento de bactérias do ácido propiônico, Propionibacterium, essenciais para a formação dos olhos característicos de queijos como o Emmenthal e, portanto, não é apropriado para controle de Clostridia neles. Além disso, ele pode reagir com aminoácidos aromáticos do queijo, formando nitrosaminas muitas das quais são carcinogênicas. Essa reação, porém, ocorre preferencialmente na faixa entre $\mathrm{pH}$ 2-4,5 de modo que na maioria dos queijos, onde o pH é mais alto, a formação de nitrosaminas é muito lenta. A maior parte do nitrato adicionado é eliminado através do lactosoro, ou difunde-se na salmoura, fazendo com que os níveis de nitrito encontrados no queijo pronto para consumo sejam, geralmente, bem menores que $50 \mathrm{mg} \mathrm{kg}^{-1}$. Mesmo assim, em alguns países o uso de nitratos na fabricação de queijos é proibido. Adição de excesso deste sal pode inibir a flora láctea, dificultando a maturação do produto e alterando sua cor e sabor. 
A cor dos queijos está intimamente ligada à gordura do leite e, por isso mesmo, é sujeita a variações sazonais que são corrigidas pela adição de corantes. No caso de queijos azuis, ou seja, aqueles com mofos esverdeados, é comum adicionar-se clorofila à massa para que esta adquira uma coloração pálida, contrastante com a do mofo. Queijos amarelos, como o Prato, podem ser corados com urucum.

Com poucas exceções, os queijos contêm entre 0,5-2,0\% de $\mathrm{NaCl}$. Queijos azuis têm em torno de 3-7\% de sal. Durante a salga do queijo, a diferença na pressão osmótica entre a salmoura e a massa faz com que parte da umidade desta seja liberada, arrastando consigo soroproteínas, ácido láctico e minerais dissolvidos, ao mesmo tempo em que o $\mathrm{NaCl}$ é absorvido. Para que este equilíbrio funcione bem é importante que a concentração da salmoura e seu $\mathrm{pH}$ sejam apropriados; além disso, o teor de cálcio do meio deve ser da ordem de $0,1-0,2 \%$ podendo ser ajustado por adição de $\mathrm{CaCl}_{2}$, se necessário. $\mathrm{O}$ pH ideal da salmoura é entre 5,2 e 5,3. Durante o processo de salga ocorre troca de íons $\mathrm{Ca}^{2+}$ por $\mathrm{Na}^{+}$nas moléculas de para-caseína, o que torna a massa mais macia. Se o pH estiver abaixo de 5,0 haverá mais íons $\mathrm{H}^{+}$do que $\mathrm{Ca}^{2+}$ ligados às moléculas de para-caseína; em consequiência, haverá incorporação insuficiente de íons $\mathrm{Na}^{+}$e o queijo ficará duro e quebradiço. Ao contrário, em pH acima de 5,8 haverá excesso de íons $\mathrm{Ca}^{2+}$ em relação aos íons $\mathrm{H}^{+}$levando a um excesso de íons $\mathrm{Na}^{+}$na molécula após a troca, deixando o queijo demasiado macio. A concentração da salmoura deve ficar entre $18-23 \%$ de $\mathrm{NaCl}$, para temperaturas entre $10-14{ }^{\circ} \mathrm{C}$, de modo a facilitar a absorção do sal, manter um grau ótimo de dissolução da para-caseína, eliminar bactérias patogênicas porventura presentes e evitar contaminação ${ }^{5}$.

\section{ALGUNS QUEIJOS E SUAS CARACTERÍSTICAS, 4, 7-10}

Camembert - originário da França onde é fabricado, na vila de mesmo nome, desde 1791. É um queijo semi-macio, pesando $110 \mathrm{~g}$ no mínimo. É fabricado com leite de vaca não-pasteurizado e sua maturação dura entre 12 e 14 dias. Apresenta-se coberto com camada branca, devida aos Penicillium camemberti e P. candidum. Acredita-se que tenha sido fabricado pela primeira vez por Madame Marie Harel, em cuja homenagem foi esculpida uma estátua que ainda hoje pode ser vista na praça de Camembert.

Cottage - coalhada fresca, cremosa, de baixa acidez, típica dos países anglo-saxônicos. Sofre lavagem contínua durante a sua produção, de modo a diminuir os teores de ácido láctico e lactose. Contém cerca de $80 \%$ de umidade e $4 \%$ de gordura. É classificado como um queijo fresco, macio, não-gorduroso.

Gruyère - obtido de leite de vaca cru ou pasteurizado, de massa cozida e prensada, deve ser maturado durante, no mínimo, quatro meses. Tem formato cilíndrico, crosta firme, grossa, de cor amareloparda. Sua consistência é semi-dura, elástica, de untura semimanteigosa; tem textura aberta, com olhadura característica, ovalada e cor amarelo-clara. Seu odor é característico, agradável e seu sabor é adocicado, levemente picante. Pesa entre 20 e $45 \mathrm{~kg}$.

Emmenthal - é em tudo semelhante ao Gruyère, mas suas olhaduras têm diâmetro maior e seu peso varia entre 60 e $120 \mathrm{~kg}$.

Minas Frescal - tipicamente brasileiro, é um dos mais consumidos no país. É produzido com leite de vaca pasteurizado; tem pouca acidez e sua durabilidade é pequena - em torno de 9 dias, sob refrigeração. É classificado como um queijo macio, semi-gordo, de alta umidade. Tem cor esbranquiçada e odor suave, característico. Deve ter formato cilíndrico e pesar entre 0,3 e $5 \mathrm{~kg}$.

Minas Padrão - também de origem brasileira, fabricado com leite pasteurizado, padronizado para 3,3-3,5\% de gordura. Diferentemente do frescal, esse produto é prensado e passa por um período de maturação de 20 dias antes de estar pronto para consumo. É um queijo de textura aberta, com poucas olhaduras pequenas, de consistência semi-dura, sabor levemente ácido e cor interna branco-creme; sua crosta é lisa, fina e amarelada. Possui cerca de $48 \%$ de umidade e $24 \%$ de gordura. Deve ter formato cilíndrico e peso entre 1 e $1,2 \mathrm{~kg}$.

Minas Curado - seu fabrico nas fazendas de Minas Gerais remonta ao período colonial. Sua produção é toda artesanal, constituindo um verdadeiro patrimônio cultural do Estado, onde são produzidas cerca de 44 mil t/ano. É feito com leite não-pasteurizado e deve ser conservado à temperatura ambiente. $\mathrm{O}$ fermento utilizado é o pingo, mistura complexa de bactérias lácteas, entre as quais Lactococcus lactis e L. cremoris. Este é retirado na segunda etapa da cura, após a salga; o sal elimina bactérias patogênicas e o fermento, por sua complexidade, é capaz de garantir não só as características, mas também a sanidade do produto. Para que tal aconteça, no entanto, é necessário respeitar o tempo de maturação que é de 20 dias $^{2}$. É um queijo de textura semi-dura, com olhaduras pequenas, sabor levemente ácido e cor creme-claro. Sua casca é amarelo-ouro.

Mussarela - queijo de origem italiana, era originalmente feito somente com leite de búfala. Ao longo do tempo foi-se modificando de modo que, atualmente, há queijos mussarela feitos também com leite de vaca e/ou mistura de leites de vaca e búfala. É um dos queijos mais fabricados e consumidos no Brasil. É produzido com leite pasteurizado, normalizado em teor de gordura. Sua massa é filada, isto é, após a dessoragem ela é finamente fatiada, aquecida e as fatias misturadas até formar um bloco liso e homogêneo com consistência firme, compacta. Tem cor esbranquiçada e sabor levemente ácido. Seu formato e peso são variáveis e deve ser conservado sob refrigeração, em temperaturas de até $10^{\circ} \mathrm{C}$.

Parmesão - queijo de baixa umidade, semi-gordo, de massa précozida e prensada. Seu tempo de maturação deve ser de, no mínimo, seis meses, podendo ultrapassar os dois anos. É um queijo de origem italiana, mas bastante popular no Brasil, fabricado com leite de vaca cru ou pasteurizado e/ou reconstituído padronizado. Possui consistência dura e textura compacta, granulosa, com crosta firme e lisa; sua cor é ligeiramente amarelada e o sabor, levemente picante, salgado. Seu odor é suave e agradável, devendo ser armazenado em temperatura não superior a $18{ }^{\circ} \mathrm{C}$. Tem formato cilíndrico e deve pesar entre 5 e $10 \mathrm{~kg}$.

Prato - é um queijo gordo, de média umidade, massa semi-cozida de consistência semi-dura e textura homogênea, com poucas e pequenas olhaduras lisas e brilhantes. Seu sabor é suave, levemente adocicado e sua cor é amarelo-ouro. Pode ter formato cilíndrico, retangular ou esférico; antes de ser consumido deve maturar por um período de 45 a 60 dias. Em média, o queijo prato possui $43 \%$ de umidade e $27 \%$ de gordura em sua composição. Feito exclusivamente de leite de vaca pasteurizado, este produto popularizou-se no Brasil como uma modificação dos queijos Danbo (dinamarquês) e Gouda (holandês); alguns autores consideram-no como derivado dos holandeses Gouda e Edam. O Danbo e o Gouda são semelhantes ao queijo Prato no que tange à cor e textura, mas possuem sabor mais acentuado. O Edam foi introduzido no Brasil em 1880. Fabricado inicialmente no município mineiro de Palmira, atual Santos Dumont, foi durante muito tempo conhecido como queijo palmira. Recebia também a denominação de queijo de cuia, devido à sua embalagem em cuia dupla feita de folha de flandres que, no entanto, já foi quase inteiramente substituída por invólucro plástico. O queijo, conhecido também como Queijo do Reino conserva, porém, seu típico formato de bola com crosta colorida de vermelho. Possui consistência semidura, pouco elástica, cor interna amarelo-palha e sabor picante; sua textura é aberta, com poucos olhos arredondados e brilhantes. Deve ser maturado por dois meses, no mínimo, e seu peso varia entre 1,8 e 2,2 kg.

Provolone - há basicamente dois tipos: 
Fresco: é o queijo de massa filada, não prensado, feito de leite pasteurizado. Tem formato variável e sua consistência, textura, cor e sabor são iguais aos do Mussarela. Deve ser consumido com até 20 dias de fabricação e seu peso varia de 0,5 a $2 \mathrm{~kg}$. Possui uma variedade chamada "Butirro" que é idêntica ao Provolone Fresco, exceto pelo fato de sua massa ser acrescida de pequena quantidade de manteiga.

Curado: obtido de leite cru ou pasteurizado, sua massa também não é prensada, mas pode ou não ser enformada. Seu formato varia do esférico ao ovalado e tem consistência dura, quebradiça e untada; sua crosta é firme e lisa, resistente, destacável, de cor amarelo-parda e deve, preferencialmente, ser revestida de parafina. Tem textura fechada podendo apresentar poucos olhos pequenos; sua cor é branco creme e possui sabor e odor próprios, fortes e picantes. Deve ser maturado pelo período mínimo de 2 meses e pesar entre 1 e $8 \mathrm{~kg}$. Segundo a especificação do MAPA, quando esse queijo apresenta formato ovalar ou cilíndrico alongado recebe o nome de "Cacciocavalo".

Quark - produto originário da Alemanha, pertence à classe dos queijos frescos. É produzido a partir de leite pasteurizado, desnatado e padronizado quanto ao teor de gordura. Pode ser feito também a partir de leite em pó desnatado, reconstituído. O Regulamento Técnico de Identidade e Qualidade de Queijos em vigor no Brasil classifica-o como queijo de muito alta umidade (não inferior a 55\%). Serve de base, acrescido de açúcar, creme de leite e frutas, para a fabricação do queijo "Petit-Suisse".

Ricota - produto obtido da albumina de soro de queijos, acrescida de até $20 \%$ de leite em volume. Deve ser consumido em, no máximo, três dias após o fabrico. Apresenta consistência mole, mas não pastosa, textura fechada, com poucos buracos, de cor branca ou branco-creme. Deve ter formato cilíndrico e peso entre 0,3 e $1 \mathrm{~kg}$.

Roquefort - obtido a partir de leite cru de ovelhas, é um queijo semiduro, não prensado. Os primeiros registros da sua fabricação datam de 1.070 d.C., mas já há referência a ele em poemas do ano 76 a.C.. Tem consistência esfarelenta e sua textura é fechada, com poucas e pequenas olhaduras. Possui odor próprio e sabor salgado e picante. Sua cor é branco-creme, com formações características, bemdistribuídas, verde-azuladas, devidas ao Penicillium roqueforti . Tem formato cilíndrico e pesa entre 2 e 2,2 $\mathrm{kg}$. Deve ser comercializado envolto em papel metalizado.

Gorgonzola - diferencia-se do Roquefort pelo fato de ser produzido a partir de leite de vaca.

\section{ASPECTOS MICROBIOLÓGICOS}

O leite utilizado na fabricação de queijos frescos tem que ser pasteurizado. Já para os queijos maturados, pode-se utilizar o leite cru desde que sejam respeitados os prazos de maturação e utilizadas as boas práticas de fabricação, que incluem desde a exigência de só utilizar leite de alta qualidade até rigorosa higiene no local de produção.

A pasteurização é um processo térmico que visa destruir os patógenos e reduzir o número de microorganismos em geral, presentes no leite e derivados. Alternativas a essa técnica são a bactofugação e a microfiltração. A primeira consiste em uma centrifugação realizada em centrífuga especial, hermética, capaz de separar o leite das bactérias e esporos; a segunda consiste em filtrar o leite através de membranas especiais, capazes de reter as bactérias indesejadas ${ }^{5}$.

A boa qualidade microbiológica do leite, seja ele pasteurizado ou cru, é fundamental para a preparação de bons queijos. Ela pressupõe um gado saudável, boas práticas de higiene na ordenha e no manuseio do leite, higienização eficiente dos equipamentos e utensílios utilizados e, finalmente, o resfriamento do leite a temperaturas entre 0-4 ${ }^{\circ} \mathrm{C}$, no máximo $2 \mathrm{~h}$ após a ordenha. Essas práticas permi- tem que o leite mantenha a qualidade microbiológica por até $72 \mathrm{~h}$, mas não significam ausência de bactérias. Inclusive porque o leite é um ótimo meio para crescimento destes microorganismos ${ }^{11}$. No Brasil essas condições são conseguidas pela maioria dos grandes produtores, mas o mesmo não pode ser dito dos médios e pequenos ${ }^{12}$.

O leite contaminado é um problema para a indústria laticinista, uma vez que se torna mais ácido, resultando em produtos de má qualidade e mais perecíveis. O nível de bactérias presentes no leite brasileiro de boa procedência é menor que $10 \% \mathrm{~mL}$, compatível com o exigido pelo MAPA. Mas se comparado, por exemplo, com a Alemanha onde $80 \%$ do leite ordenhado tem menos que 20 mil bactérias/mL o nosso índice de contaminação ainda é muito alto ${ }^{12}$. Essa contaminação acarreta barreiras não tarifárias para a exportação de laticínios brasileiros além de constituir risco à saúde da população no país. Basta lembrar que o gado brasileiro não está livre de doenças como febre aftosa, tuberculose e brucelose, que podem ser transmitidas ao homem através do leite e derivados. Segundo dados recentes $^{13}$, a tuberculose bovina atinge cerca de $8 \%$ do rebanho nacional, o que representa perto de 14 milhões de animais. Este problema é mais grave se considerarmos que o resfriamento não destrói os microorganismos, nem inibe a ação de suas enzimas, apenas torna-a mais lenta. Alguns microorganismos são até mesmo capazes de reproduzir-se bem em temperaturas próximas a $0{ }^{\circ} \mathrm{C}$; entre estes encontram-se bactérias produtoras de lipases e proteases que alteram a qualidade nutricional do leite.

Durante a transformação do leite em queijo ocorre, paralelamente à oxidação da lactose, a redução do oxigênio dissolvido. Em consequência, o interior dos queijos torna-se um ambiente essencialmente anaeróbico onde, portanto, só crescem microorganismos anaeróbicos. Isso significa que microorganismos exclusivamente aeróbicos como Pseudomonas, Brevibacterium, Bacillus e Micrococcus podem desenvolver-se na superfície dos queijos, mas não em seu interior ${ }^{14}$.

Do ponto de vista do crescimento e da resistência ao calor, os microorganismos de maior importância na indústria de laticínios podem ser agrupados $\mathrm{em}^{11}$ :

- Mesófilos: microorganismos cuja temperatura ótima de crescimento é em torno de $32{ }^{\circ} \mathrm{C}$, mas que podem crescer entre 10 $45^{\circ} \mathrm{C}$. Este grupo inclui a maioria dos contaminantes do leite.

- Psicotróficos: são capazes de crescer sob refrigeração, embora a maioria encontre condições ótimas de crescimento em temperaturas maiores que $20{ }^{\circ} \mathrm{C}$. É um grupo importantíssimo em produtos que são conservados sob refrigeração por períodos entre 1-4 semanas. Além disso, com o uso intensivo de refrigeração no manuseio do leite e seus derivados, espécies mesófilas têm sofrido adaptação seletiva, tornando-se psicotróficas.

- Termofílicos: os microorganismos deste grupo são capazes de sobreviver às condições de pasteurização. Do ponto de vista de crescimento, alguns deles são psicotróficos.

Do ponto de vista bioquímico ${ }^{11,14}$, a microbiota dos queijos pode ser dividida em dois grupos: bactérias lácticas iniciadoras (BLI) e microorganismos secundários. As primeiras são responsáveis pela transformação de lactose em ácido láctico durante a preparação do queijo; suas enzimas também contribuem na maturação, estando envolvidas na proteólise e na conversão de aminoácidos em substâncias voláteis responsáveis pelas propriedades organolépticas do produto. Por serem de crescimento rápido, estes microorganismos podem estragar o leite por acidificação se sua ação não for controlada. Por outro lado, são indispensáveis para a fabricação dos queijos. As BLI podem ser adicionadas no início da produção, ou podem-se utilizar somente aquelas que já ocorrem naturalmente no leite. Este último caso é o normalmente utilizado na fabricação de queijos artesanais a partir de leite não pasteurizado. 
Dependendo do queijo utilizam-se culturas mesofílicas - por exemplo, queijos Gouda, Edam e Camembert - ou termofílicas. Essas últimas são utilizadas principalmente na fabricação de queijos cozidos que passam por temperaturas acima de $50{ }^{\circ} \mathrm{C}$ como, por exemplo, Parmesão, Emmenthal e Gruyère. Entre os gêneros mais comuns usados como BLI incluem-se Lactococcus, Lactobacillus, Streptococcus, Leuconostoc e Enterococcus.

Para fabricação de queijos podem-se utilizar culturas definidas um número conhecido de cepas conhecidas - ou culturas mistas nas quais tem-se um número desconhecido de cepas. As culturas mesofílicas utilizadas, definidas ou mistas, são constituídas principalmente de Lactococcus lactis ssp. cremoris e L. lactis ssp. lactis; já as termofílicas mais comuns são compostas de Streptococcus thermophilus e bacilos lácticos como Lactobacillus delbrueckii ssp. delbrueckii, Lb. delbrueckii ssp. bulgaricus, Lb. delbrueckii ssp. lactis ou Lb. helveticus. É interessante observar que, em geral, várias cepas convivem nessas culturas; umas são mais resistentes aos fagos do que outras, algumas têm menor capacidade de produção de ácido, de modo que elas se autocontrolam impedindo, inclusive, a proliferação exagerada de microorganismos indesejados. A presença de bactérias do gênero Enterococcus como parte da microbiota natural de alguns queijos artesanais já foi causa de muito debate, uma vez que existem evidências de que elas estejam associadas a infecções desenvolvidas por pessoas com comprometimento do sistema imunológico. Outra fonte de preocupação é que algumas cepas dessas bactérias são resistentes à vancomicina, antibiótico utilizado no combate a infecções gerais. Apesar dessas preocupações elas são encontradas em diversos queijos, especialmente os da região mediterrânea, e acredita-se que tenham forte e positivo efeito sobre o desenvolvimento de seus aromas e sabores ${ }^{14}$.

Os microorganismos secundários compreendem as bactérias lácticas não-iniciadoras (BLNI), que crescem no interior da maioria das variedades de queijos, e outras bactérias, leveduras e/ou fungos que crescem, tanto no interior, quanto na parte externa dos queijos e são característicos de uma variedade específica ou de um grupo de tipos intimamente relacionados. Entre estes microorganismos estão os proteolíticos, os lipolíticos, e os produtores de gás ${ }^{11,14}$.

Os microorganismos proteolíticos, como o nome indica, são responsáveis pela quebra de proteínas. Em sua ação, provocam alterações no aroma, sabor e características físico-químicas do leite e derivados. Embora os microorganismos tipicamente proteolíticos sejam indesejáveis, certas bactérias lácticas possuem alguma atividade proteolítica, a qual é importantíssima na maturação dos queijos. Fazem parte deste grupo as Pseudomonas, Achromobacter, Flavobacterium e Bacillus. Associados aos microorganismos proteolíticos, e geralmente tão indesejáveis quanto eles, estão os lipolíticos, responsáveis pela quebra nas gorduras que acarreta como principal problema, o ranço. A maioria deles tem características psicotróficas. Entre os microorganismos lipolíticos encontram-se bactérias como Pseudomonas e Alcaligenes e fungos, como Candida e Geotrichum ${ }^{11}$.

Os microorganismos produtores de gás podem ser encontrados em quaisquer dos grupos anteriores. Alguns produzem efeitos indesejáveis, outros são fundamentais para que o queijo desenvolva sua textura própria. Às vezes, a quantidade destes microorganismos é que vai determinar se sua ação será ou não indesejável. Alguns dos mais comuns são dos gêneros Clostridium, Candida, Saccharomyces $e$ Coliformes, sendo que a presença deste último indica falta de higiene adequada no manuseio e processamento dos produtos.

É interessante ressaltar que a espécie e as cepas dominantes na microbiota secundária variam durante o período de maturação do queijo.

Alguns microorganismos patogênicos, como espécies de Staphylococcus, podem ser encontrados em laticínios. Eles são res- ponsáveis por sérias intoxicações alimentares, devido às toxinas que formam durante as fases de processamento e armazenamento dos produtos. Um artigo recente ${ }^{15}$ relata que, entre 1995 e 2001, ocorreram em Minas Gerais 23 surtos de intoxicação provocados pela ingestão de queijos contaminados com S. aureus; um total de 660 pessoas foram intoxicadas e uma delas morreu em consequiência. Este microorganismo pode ser eliminado ou sua capacidade de produzir toxinas inibida por irradiação com raios- $\gamma$ como relatado por Amaral Gurgel et al. ${ }^{16}$, de modo que esta técnica pode vir a ser uma ferramenta auxiliar na melhoria da qualidade microbiológica de queijos. Agentes infecciosos, como Shigella e Salmonella, também podem contaminar produtos lácteos e infectar seus consumidores ${ }^{11}$.

Um grande problema enfrentado pela indústria de laticínios em todo o mundo é a infecção fágica ${ }^{17}$, responsável por vultosas perdas econômicas. Nela, bactérias lácticas são atacadas por vírus, de modo que há produção insuficiente de ácido láctico e conseqüente falha na fermentação do leite. Por atacarem bactérias estes vírus são chamadas bacteriófagos, ou simplesmente fagos, e muitos deles são resistentes às condições de pasteurização, pouco afetados por alterações de $\mathrm{pH}$ do meio e capazes de sobreviver por longos períodos, em estado de dormência, sob refrigeração, congelamento e mesmo sob forma seca. Cada célula infectada por um bacteriófago pode liberar até 200 novas partículas virais, acarretando uma contaminação ambiental de vulto nas grandes indústrias. Além disso, como a relação fago/bactérias lácticas é muito dinâmica, mutantes bacterianos resistentes eventualmente isolados perdem a resistência em pouco tempo, nas condições industriais. A melhor forma de combate à infecção fágica é manter higiene rigorosa em todo o processo de fabricação, com salas separadas para a preparação do fermento e do queijo e evitando a dispersão do lactosoro no ambiente de produção, ou seu transporte em recipientes usados para o leite, sem prévia e rigorosa higienização.

A contaminação microbiológica na indústria de alimentos representa um sério perigo para a saúde do consumidor e acarreta grandes prejuízos econômicos. Os laticínios, pela própria matéria-prima que utilizam e pelo alto teor de umidade nos locais de produção, são particularmente suscetíveis a essa contaminação. Daí, a importância da conscientização dos profissionais do setor, em todos os níveis, para a necessidade da implantação de programas de boas práticas de fabricação e do controle permanente dos processos e seus pontos críticos.

\section{MATURAÇÃO}

Consiste em uma série de processos físicos, bioquímicos e microbiológicos que ocorre em todos os queijos, exceto aqueles que são consumidos frescos. Estes processos alteram a composição química dos queijos, principalmente no que tange a seu conteúdo em açúcares, proteínas e lipídeos. O tempo de maturação varia para cada tipo e é neste processo que se desenvolvem as características organolépticas e de textura, características de cada um deles.

A maturação dos queijos é feita, na maioria dos casos, em câmaras com controle de temperatura e umidade. O tempo varia de acordo com o tipo, podendo ir de poucas semanas a muitos meses. Tradicionalmente o índice de maturação é medido pela degradação de caseína, através da avaliação da proporção entre nitrogênio total e nitrogênio solúvel, assim denominado o nitrogênio oriundo de matéria orgânica. Este índice deve aumentar com o avanço da maturação. Recentemente a eletroforese capilar tem sido utilizada para acompanhar a degradação da caseína e, portanto, o avanço da maturação ${ }^{18}$. Tentativa de utilizar a espectroscopia no infravermelho próximo (NIR) para determinar o grau de maturação de queijos não apresentou o resultado esperado, já que não houve alteração significativa nos pa- 
drões espectrais observados nessa região ${ }^{19}$. A literatura registra ainda o acompanhamento do estágio de maturação de queijos usando o ultra-som, que tem a vantagem de ser uma técnica não destrutiva e permitir detectar, simultaneamente, defeitos oriundos de fermentação anormal ${ }^{20}$.

O principal processo ocorrido na maturação, especialmente dos queijos duros, é a degradação das proteínas ou proteólise. Esta é efetuada pelos sistemas enzimáticos do coalho e é fator preponderante para a qualidade do queijo, sobretudo nos aspectos sabor e consistência. Em queijos cuja massa é cozida em altas temperaturas - por exemplo, o Gruyère, que é cozido a $52{ }^{\circ} \mathrm{C}$ - ou nos de massa escaldada como o Parmesão, a plasmina é a principal enzima proteolítica. Em queijos semi-duros, como o Tilsit, ocorrem dois processos simultâneos de maturação: um, o usual, ocorre no interior da massa, onde as ligações peptídicas das proteínas são quebradas, liberando peptídeos pequenos e aminoácidos; o outro ocorre na casca onde as proteínas podem ser degradadas até a formação de amônia ${ }^{5,14}$. Não existe uma correlação direta entre o aroma dos queijos e a concentração de aminoácidos livres. Sabe-se, no entanto, que estes podem ser metabolizados por enzimas bacterianas produzindo produtos menores, entre os quais flavorizantes. Jollivet et al. ${ }^{21}$, por exemplo, relataram que Brevibacterium linens produz amônia, aminas, álcoois, aldeídos e os ácidos capróico e 3-metilbutírico a partir de aminoácidos; todos esses produtos influenciam, em maior ou menor grau, o sabor e o aroma dos queijos. Produtos da degradação de aminoácidos contendo enxofre desempenham papel particularmente importante. L-metionina, por exemplo, pode ser degradada a S-metiltioésteres e metanotiol ao qual se atribui o odor característico de queijos como Gruyère, Comté e outros. Já o sabor amargo que, às vezes, se observa em alguns queijos é atribuído à liberação excessiva de peptídeos de baixo peso molecular. A Figura 1 apresenta um esquema geral da degradação de aminoácidos em queijos.

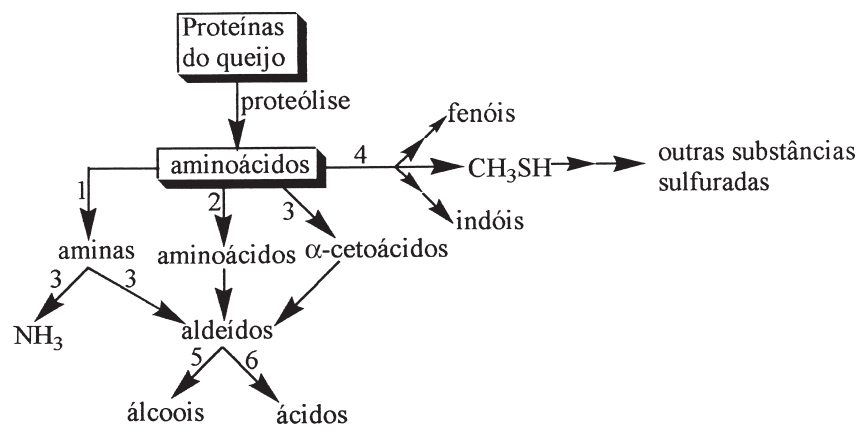

Figura 1. Esquema geral de proteólise decorrente da ação microbiana durante a maturação de queijos: $1=$ descarboxilação; 2=transaminações; $3=$ desaminações oxidativas; $4=$ degradações; $5=$ reduções; $6=$ oxidações

As enzimas da microbiota secundária responsáveis pela degradação de aminoácidos são basicamente transaminases, desaminases e carboxilases. As primeiras catalisam a transferência do grupo amino de um $\alpha$-aminoácido a um $\alpha$-cetoácido e atuam sobre um amplo espectro de substratos. Cistationina liases, por exemplo, são enzimas dependentes do piridoxal-5-fosfato que podem metabolizar a cistationina produzindo cisteína, ácido $\alpha$-cetobutírico e amônia, através de reação de eliminação $\alpha, \gamma$, ou produzindo, por eliminação $\alpha, \beta$, homocisteína, ácido pirúvico e amônia (Esquema 1) (22. $^{22}$.

Um estudo recente ${ }^{23}$ realizado com uma variedade de queijo Gouda, denominada Norvegia, mostrou que o tratamento inicial do leite utilizado para a fabricação do produto pode influenciar a sua composição química após maturação. Queijos feitos com leite pasteurizado apresentaram menor teor de piruvato e alanina e maior

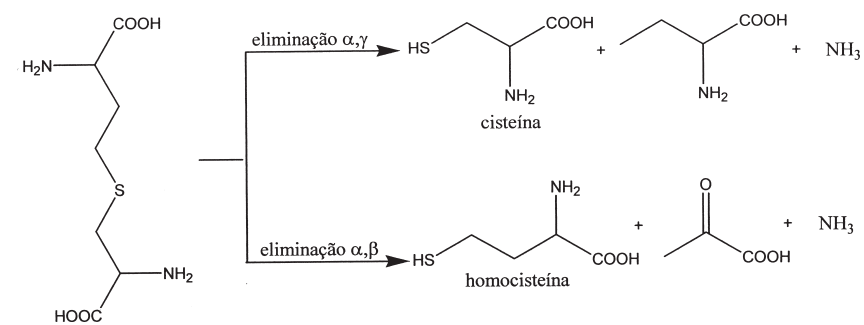

Esquema 1. Esquema de degradação enzimática da cistationina em queijos

quantidade de lactato, citrulina e tirosina do que aqueles fabricados com leite tratado apenas por microfiltração. Além disso, os mesmos autores observaram que adição de uma carga extra de Lactobacillus ao leite utilizado, independente do tratamento prévio a que ele tenha sido submetido, induz a degradação mais rápida dos aminoácidos e, em conseqüência, aumenta a concentração de ácidos orgânicos livres no produto final.

O principal açúcar dos queijos é a lactose e sua degradação, conhecida como fermentação láctica, ocorre também na maturação. Tal degradação é efetuada por bactérias do próprio leite e deve ser controlada tanto em extensão, quanto na velocidade com que ocorre. Em alguns queijos, como por exemplo o Cheddar, é importante que a fermentação láctica ocorra ainda na fase de formação da coalhada. Em outros, é necessário controlá-la para que ocorra em maior extensão durante a prensagem e as primeiras semanas de armazenamento $^{22}$.

O ácido láctico formado na fermentação do leite apresenta-se no queijo, principalmente sob a forma de lactato. Este sal é o substrato adequado para bactérias como Propionibacterium, que constituem boa parte da microbiota de queijos tipo Emmenthal, Gruyère e similares. Neles, a degradação da lactose segue a via da fermentação propiônica, levando à formação de sais dos ácidos propiônico e acético, além de quantidades apreciáveis de $\mathrm{CO}_{2}$, que é o responsável direto pela formação dos olhos característicos desses queijos ${ }^{14,24}$.

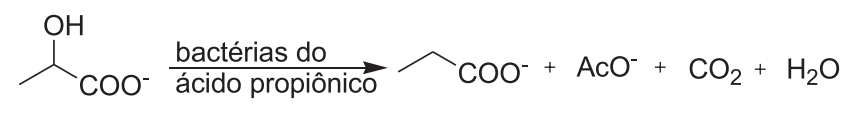

Em queijos contendo quantidade maior que o normal de bactérias do gênero Clostridium ocorre paralelamente uma outra rota, a fermentação butírica ${ }^{14,24}$. Nela, o lactato é transformado em butirato com concomitante formação de $\mathrm{CO}_{2}$ e $\mathrm{H}_{2}$, responsável pelo estufamento dos queijos durante a maturação. Esse defeito, conhecido como estufamento tardio, caracteriza-se pela formação de buracos grandes na massa podendo, em casos mais graves, ocorrer também rachaduras na casca.

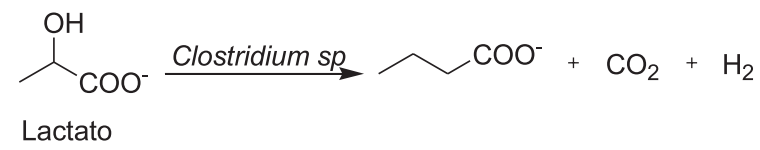

Das espécies de Clostridium que ocorrem no leite, as mais comumente envolvidas na fermentação inadequada são $C$. butyricum, C. esporogenes e C. tyrobutyricum, sendo que esta última é geralmente apontada como a principal responsável pelo estufamento tardio. No entanto, em um estudo realizado por Mesquita et al. ${ }^{25}$, o microorganismo mais freqüentemente encontrado em amostras estufadas de queijos provolone, parmesão e prato, fabricados no Brasil, foi $C$. butyricum. A principal fonte de bactérias do gênero Clostridium no leite é a silagem de baixa qualidade usada como alimento do 
gado, mas elas podem advir também de contaminação com esterco durante a ordenha. Segundo a literatura ${ }^{24,25}$, não há consenso sobre o número mínimo de esporos capazes de provocar o defeito, mas sabese que acima de 200 esporos de Clostridium por litro de leite já ocorre o estufamento.

Essas bactérias utilizam como substrato também outros açúcares, como a galactose, a sacarose e a glicose; a fermentação desta produz, além de ácido butírico, dióxido de carbono e hidrogênio, os ácidos propiônico e acético, acetona, butanol e etanol.

A fermentação butírica é indesejável, não só pelo estufamento que provoca e que, dependendo do grau em que ocorre, pode tornar o queijo completamente impróprio para comercialização, mas também porque confere ao queijo forte odor a ranço e sabor desagradável. A concentração de ácido butírico capaz de modificar o sabor do queijo varia de acordo com o tipo; no Gouda, por exemplo, isso ocorre em concentrações acima de $500 \mathrm{mg} \mathrm{kg}^{-1}$; já no Emmenthal, o sabor é modificado sempre que a proporção entre os ácidos propiônico e butírico for inferior a $1^{24}$.

Queijos como Emmenthal e Gruyère são particularmente sensíveis à fermentação butírica. Já no Camembert ela nunca ocorre. Acredita-se que esta diferença de comportamento se deva a uma conjunção de fatores, entre os quais as diferentes temperaturas de fabricação desses queijos, os seus teores de sal e umidade, o pH da massa e até a embalagem utilizada que pode, ou não, facilitar a expulsão dos gases formados.

A diferença de comportamento entre $\mathrm{CO}_{2}$ e $\mathrm{H}_{2}$ na maturação dos queijos está diretamente ligada a suas solubilidades em água. O primeiro, bastante solúvel, só provoca olhaduras na massa quando sua concentração é suficiente para saturar completamente o meio em que está dissolvido. É por isso que queijos cuja massa é precocemente submetida a altas temperaturas apresentam maior número de olhaduras, já que nessas condições a solubilidade do $\mathrm{CO}_{2}$ diminui. Já o hidrogênio, não sendo hidrossolúvel, forma olhos na massa tão logo se forme ${ }^{24}$.

Durante o processo de maturação ocorre ainda a lipólise das gorduras com formação de ácidos graxos de baixo peso molecular. Tais reações ocorrem por ação dos microorganismos presentes e/ou através de enzimas adicionadas especificamente para esse fim. Os principais ácidos formados são butírico, capróico, caprílico, cáprico e láurico; sua proporção relativa varia de acordo com o agente lipolítico utilizado o qual, por sua vez, é escolhido de acordo com o queijo. Por exemplo, ácido butírico é fundamental para o sabor e aroma do provolone. Já no roquefort o Penicillium roqueforti produz uma lipase hidrossolúvel que induz a formação, principalmente, dos ácidos capróico, caprílico e cáprico responsáveis pelo seu odor e sabor característicos ${ }^{5}$.

Embora a maturação esteja longe de ser um processo completamente entendido, já se sabe que a glicólise é efetuada integralmente pela microbiota láctica iniciadora, enquanto a lipólise e a proteólise requerem a participação também da microbiota secundária para se completarem $^{22}$.

O processo de maturação é caro pois demanda, em geral, instalações especiais com temperatura e umidade controladas; além disso, diminui o capital de giro do produtor por retardar a comercialização do produto. Em alguns casos, pressões financeiras e comerciais têm levado produtores brasileiros a vender seus queijos antes do tempo adequado de maturação, acarretando falta de homogeneidade e perda de qualidade do produto. Este comportamento, certamente, acarretará prejuízos no longo prazo e, no caso de derivados de leite cru, representa um risco à saúde do consumidor.

A necessidade de diminuir o tempo de maturação dos queijos, sem alterar suas características nutricionais e organolépticas, é uma questão mundial e desperta interesse em pesquisadores de diversos países. Os métodos testados são vários, envolvendo adição de carga extra de bactérias lácteas ou de extrato celular delas, hidrólise parcial prévia da lactose, uso de bactérias lácteas modificadas, adição de enzimas exógenas, bem como irradiação com raios $\mathrm{X}$ e raios $\gamma^{9}$.

Um estudo realizado por Minussi et al. ${ }^{26}$ conseguiu reduzir o tempo de maturação do queijo prato de 60 para 45 dias, usando cultura de bactérias em meio hidrolisado. Já Dilanian et al. ${ }^{27}$ conseguiram, através de irradiação com raios X e $\gamma$, cepas mutantes de bactérias lácteas, que foram usadas na produção de queijos Armianski e Sovetski; estes não só atingiram o ponto ideal de maturação em tempo menor, mas também tiveram sua qualidade melhorada. Adição de $\alpha$-cetoglutarato, um aceptor de transaminase, à coalhada na fabricação de Cheddar resultou em aceleração da maturação e intensificação de seu aroma ${ }^{28}$.

A pesar dos vários estudos já registrados na literatura este é um assunto ainda em aberto e que demanda um número maior de pesquisas.

\section{CONTAMINAÇÃO QUÍMICA}

Aminas biogênicas são bases orgânicas alifáticas, cíclicas, de baixo peso molecular, produzidas pelo metabolismo de seres vivos em geral. São, por vezes, encontradas em alimentos e bebidas cuja produção envolve fermentação e/ou maturação. Acredita-se que sejam biossintetizadas pela descarboxilação enzimática de aminoácidos.

O queijo é um excelente meio para produção dessas aminas já que possui as condições apropriadas de $\mathrm{pH}$, concentração salina e teor de umidade para sua biossíntese, além dos aminoácidos e bactérias capazes de descarboxilá-los. Entre as bactérias capazes de produzir as aminas biogênicas têm-se espécies de Escherichia, Enterobacter, Salmonella, Shigella, Clostridium, Streptococcus, Lactobacillus e Leuconostoc. Algumas destas estão presentes no queijo como parte de sua microbiota habitual outras, em decorrência de contaminação.

Em níveis baixos de concentração, as aminas biogênicas não representam um risco sério à saúde, mas podem tornar-se perigosas se o consumo do alimento contaminado for grande ou se as rotas normais de catabolismo das aminas estiverem bloqueadas no consumidor. A Figura 2 apresenta as estruturas de algumas das aminas biogênicas encontradas em queijos.
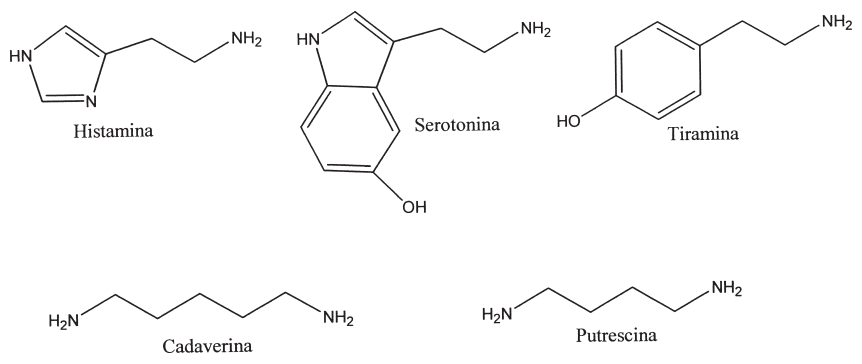

Figura 2. Representação das estruturas de algumas aminas biogênicas encontradas em queijos

Já foram relatados casos de crise hipertensiva, acompanhada de forte dor de cabeça em pessoas que ingeriram alimento contaminado com tiramina. Há relatos ainda de crises de enxaqueca após consumo de queijo contendo triptamina e 2-feniletilamina. Em pessoas em uso de drogas inibidoras da monoamino oxidase, as aminas biogênicas podem provocar a morte por hemorragia cerebral ${ }^{29}$. Em presença de nitritos essas aminas podem formar N-nitrosaminas, as quais têm comprovada ação carcinogênica, mutagênica e terato- 
gênica $^{30}$. Como já foi mencionado anteriormente, porém, a reação de formação de nitrosaminas é lenta em queijos e o teor de nitritos encontrado neles, baixo. Um estudo realizado com amostras do queijo francês Saint-Paulin ${ }^{31}$ preparadas com leites com e sem adição de nitrato, não demonstrou correlação entre o teor deste sal e a presença de nitrosaminas no queijo.

Algumas aminas, como putrescina e cadaverina, podem potencializar a ação da histamina, a qual pode provocar intoxicações graves, além de estar envolvida em mecanismos que desencadeiam ataques de asma. Não foi definido um limiar acima do qual os efeitos nocivos das aminas biogênicas ocorrem, pois este depende das condições de cada indivíduo.

Vale e Glória ${ }^{29}$ analisaram a presença de aminas biogênicas em 46 amostras de queijos fabricados no Brasil, usando a técnica de HPLC em fase reversa. As substâncias foram detectadas em grande parte das amostras, em teores que variaram entre 0,79 e $12,76 \mathrm{mg} \mathrm{g}^{-1}$. As aminas mais freqüentemente encontradas foram histamina, tiramina, 2-feniletilamina, serotonina, putrescina e cadaverina. As autoras concluíram que a acidez do queijo influencia a formação das aminas, o que estaria de acordo com a teoria de que sua síntese seria um mecanismo de proteção de bactérias contra ambientes ácidos. Mais recentemente, Fernandez-Garcia et al..$^{32}$ verificaram que a adição de proteinases exógenas à coalhada, com o intuito de acelerar a maturação do queijo tipo Manchego, não favorece o crescimento de organismos produtores de aminas biogênicas. No entanto, eles concluíram que a adição de proteinase ao leite altera a proteólise do queijo, fornecendo substratos adequados para a sua formação.

\section{CONCLUSÕES}

Apesar de bastante estudados, os processos envolvidos na maturação dos queijos ainda não são integralmente compreendidos; sua aceleração é uma demanda mundial dos produtores, mas não existe um processo geral capaz de promovê-la em larga escala.

Com relação aos queijos fabricados no Brasil, há necessidade de se conhecer mais profunda e detalhadamente os constituintes responsáveis pelo seu aroma, textura e sabor, bem como os processos através dos quais eles se formam. É importante, também, conhecer em profundidade os fatores responsáveis pelos defeitos observados neles como, por exemplo, o amargor e o estufamento; esse conhecimento certamente irá contribuir para a padronização e a melhoria da qualidade, agregando maior valor ao produto nacional.

\section{REFERÊNCIAS}

1. http://www.efr.hw.ac.uk/Das/cheese1.html; http://cheesenet.wqx.com/ cheesenet/library; http://www.franceway.com/cheese, acessadas em Dezembro 2002; http://www.cienciadoleite.com.br/art.php3, acessada em Novembro 2002.
2. Cerri, C.; de Souza, E.; Globo Rural 2002, 17, 36.

3. Cichoscki, A. J.; Valduga, E.; Valduga, A. T.; Tornadijo, M. E.; Fresno, J. M.; Food Control 2002, 13, 329.

4. www.agricultura.gov.br/das/dipoa, acessada em Outubro 2002.

5. http://www.infoleche.com/DERIVADO/quesos/quesosmanual.html, acessada em Outubro 2002.

6. http://www.fao.org/ag/AGA/AGAP/Dairyman/Dairy/V1U10_3.htm, acessada em Janeiro 2003.

7. Montes,K. J. P.; Bragança, M. G. L.; de Souza, C. M.; http:// www.emater.mg.gov.br, acessada em Novembro 2002; http:// www.agricultura.gov.br/das/dipoa/regqueijominasfrescal.html e http:// www.agridata.mg.gov.br/pesquisas/tecnologia_queijo/ patecfaminaspadrao.htm, acessadas em Setembro 2002.

8. Boletim do Leite 1983. LV, 32; ibid., 24; ibid., 42.

9. Gutierrez, E. M. R.; Tese de Doutorado, Universidade de São Paulo, Brasil, 2001.

10. Veiga, P. G.; Viotto, W. H. Ciênc. Tecnol. Aliment., Campinas 2001, 21, 267.

11. De Oliveira, J. S.; Revista da Fundação João Pinheiro 1976, 6, 26.

12. Lima Jr., A. C. de S.; Boletim do Leite 2002, 9, 1.

13. Fioravante, C.; Pesquisa Fapesp 2002, 81, 37.

14. Beresford, T. P.; Fitzsimons, N. A.; Brennan, N. L.; Cogan, T. M.; Int. Dairy J. 2001, 11, 259.

15. Do Carmo, L. S.; Tese de Doutorado, FUNED - MG, Brasil, 2001 apud Minas Faz Ciências (Fapemig) 2002, 11, 25.

16. Amaral Gurgel, M. S. C. C. do; Spoto, M. H.F .; Domarco, R. E.; Higiene Alimentar 1999, 13, 65.

17. http://www.ital.org.br/tecnolat/boletim.html, acessada em Novembro 2002.

18. Otte, J.; Ardo, Y.; Weimer, B.; Sorensen, J.; Bull. Int. Dairy Federation 1999, 337, 10; Izawa, N.; Izumi, T.; Asakawa, S.; Hayashi, K. J.; Jpn. Soc. Food Sci. Technol. 1997, 44, 871; resumos publicados em Food Sci. and Technol. Abstracts - FSTA. Current 1990-2003/01, disponível em http:// www.periodicos.capes.gov.br.

19. Wittrup, C.; Norgaard, L.; J. Dairy Sci. 1998, 81, 1803.

20. Benedito, J.; Carcel, J.; Gisbert, M.; Mulet, A.; J. Food Science 2001, 66, 100.

21. Jollivet, N.; Bessenger, M. C.; Vayssier, Y.; Belin, J.M. Appl. Environ. Microbiol. 1992, 36, 790 apud ref. 22.

22. Curtin, A.C .; Gobbetti, M.; McSweeney, P. L. H.; Int. J. Food Microbiol. 2002, 76, 231.

23. Skeie, S.; Lindberg, C.; Narvhus, J.; Int. Dairy J. 2001, 11, 399.

24. Furtado, M. M.; Rev. Inst. Lat. Cândido Tostes 1985, 40, 3.

25. Mesquita, A. J. de; Oliveira, A. N. de; Borges, G. T.; Nicolau, E. S.; Souza, A. A. G.; Ciência Animal Bras. 2001, 2, 27.

26. Minussi, R. C.; Furtado, M. M.; Mosquim, M. C. A. V.; Rev. Inst. Lat. Cândido Tostes 1995, 50, 31 apud ref. 9.

27. Dilanian, Z.; Makaria, K.; Chuprina, D.; Milchwissenschaft 1976, 31, 217 apud ref. 9.

28. Banks, J. M.; Yvon, M.; Gripon, J. C.; de la Fuente, M. A.; Brechany, E. Y.; Williams, A. G.; Muir, D. D.; Int. Dairy J. 2001, 11, 235.

29. Vale, S.; Glória, M. B. A.; Food Chem. 1998, 63, 343.

30. Oliveira, C. P.; Glória, M. B. A.; Barbour, J. F.; Scanlan, R. A.; J. Agr. Food Chem. 1995, 43, 967.

31. Bouchikhi, B.; Mavelle, T.; Debry, G.; Eur. Food Res. Technol. 1999, 209, 88; resumo publicado em Food Sci. and Technol. Abstracts - FSTA. Current 1990-2003/01, disponível em http://www.periodicos.capes.gov.br.

32. Fernandez-Garcia, E.; Tomillo, J.; Nunez, M.; Int. J. Food Microbiol. 1999, $52,189$. 